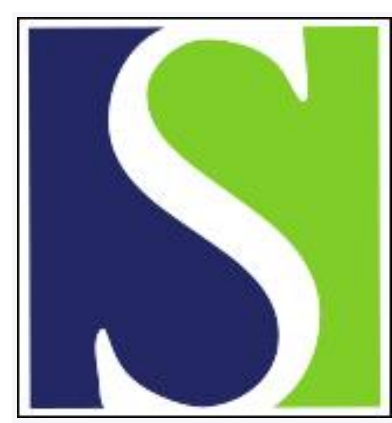

Scand J Work Environ Health 1990;16(4):239-246

https://doi.org/10.5271/sjweh.1789

Issue date: 01 Aug 1990

Birth defects among children born to a population occupationally exposed to pesticides in Colombia.

by Restrepo M, Munoz N, Day N, Parra JE, Hernandez C, Blettner M, Giraldo A

Affiliation: Instituto Nacional de Salud, Sanidad del Ambiente, Bogota, Colombia.

This article in PubMed: www.ncbi.nlm.nih.gov/pubmed/2389130

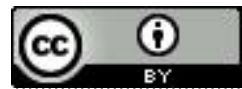




\title{
Birth defects among children born to a population occupationally exposed to pesticides in Colombia
}

\author{
by Mauricio Restrepo, MD, ${ }^{1}$ Nubia Muñoz, MD, ${ }^{2}$ Nicholas Day, PhD, ${ }^{3}$ José E Parra, MS, ${ }^{1}$ \\ Carlos Hernandez, MD, ${ }^{1}$ Maria Blettner, PhD, ${ }^{2,4}$ Alejandro Giraldo, MD ${ }^{1}$
}

\begin{abstract}
RESTREPO M, MUÑOZ N, DAY N, PARRA JE, HERNANDEZ C, BLETTNER M, GIRALDO A. Birth defects among children born to a population occupationally exposed to pesticides in Colombia. Scand $J$ Work Environ Health 1990;16:239-46. A case-referent study of birth defects was nested in a prevalence survey of adverse reproductive outcomes carried out among 8867 floriculture workers in Bogotá, Colombia. A total of 535 children born to these workers and reported by their parents as malformed and 1070 children selected at random as referents were invited to a medical examination including consultation with a geneticist and a clinical teratologist and a review of the medical records. Seventy-six percent of both groups attended the examination. Of 403 children reported as malformed, a birth defect was confirmed for only $154(38 \%)$. On the other hand, of the 817 children reported as normal, $735(90 \%)$ were normal, but 68 had a birth defect and 14 had other conditions. A case-referent analysis was then carried out including 222 children with birth defects and 443 referents. An increased risk was found only for birthmarks, and specifically for hemangiomas, for children with parents exposed to pesticides in the floriculture industry.
\end{abstract}

Key terms: adverse reproductive outcome, birthmarks, case-control study, case-referent study, floriculture, hemangioma, malformation.

It is widely accepted that abnormalities of prenatal origin that seriously interfere with viability or physical well-being have multiple causes (1).

Over the past two decades, knowledge of the causes of congenital malformations has changed considerably, and several chemical and biological teratogens have been recognized. Although it has been estimated that about $65-70 \%$ of major congenital malformations, which affect approximately $2-3 \%$ of newborn children, are caused by unknown agents (2), a recent report on a hospital-based surveillance of 69277 newborn infants in Boston has shown that $43 \%$ are of unknown etiology and some of these could be due to developmental events that are unrelated to environmental agents (3).

Chemical substances, both in the occupational setting and in the general environment, have aroused much public and scientific concern as possible teratogens. In fact, on the basis of experimental evidence, many of these substances are suspected of being embryotoxic, although most of these suspicions have not been confirmed $(1,4)$. Moreover, there is evidence indicating that certain environmental exposures (ie, ex-

1 Instituto Nacional de Salud, Sanidad del Ambiente, Bogotá, Colombia.

2 International Agency for Research on Cancer, Lyon Cédex, France.

${ }^{3}$ MRC Biostatistics Unit, Cambridge, United Kingdom.

4 Institute of Epidemiology and Biometry, German Cancer Research Center, Heidelberg, Federal Republic of Germany.

Reprint requests to: Dr N Muñoz, International Agency for Research on Cancer, 150 cours Albert-Thomas, F-69372 Lyon Cédex 08, France. posures to lead and alcohol) can be harmful to the fetus without causing an increase in malformations. Exposure to chemicals in certain occupations may be one of the factors underlying the social class gradient seen in the prevalence of malformations in several countries (5).

Because of its ubiquity and insidiousness, exposure to pesticides, occupational and environmental, has been the subject of great concern in view of its possible role in the induction of congenital malformations. In spite of this concern, very few epidemiologic studies have been conducted to ascertain the possible relationship (6-17). So far, no maternal preconceptional or prenatal exposure to pesticides has been recognized as teratogenic (1).

This investigation was initially motivated by Colombian newspaper reports suggesting an association between exposure to pesticides and cleft lip and palate in the department of Tolima where pesticides were being used intensively in cotton and rice cultures. The present study was designed to ascertain the possible association between occupational exposure to a heterogeneous group of pesticides used in the floriculture industry in Bogotá, Colombia, and the occurrence of congenital malformations and other congenital defects in humans. A case-referent study was nested in a prevalence survey of adverse reproductive outcomes among floriculture workers (18).

\section{Subjects and methods}

The floriculture industry is located on the Bogotá plateau at $2653 \mathrm{~m}$ above sea level. The mean temper- 
ature is $13^{\circ} \mathrm{C}$ without seasonal variations in the weather and with two periods of rain, one in May and the other in November. The flowers are grown for export in semiclosed polyethylene greenhouses. The importance of this relatively new enterprise can be deduced from the fact that $90 \%$ of the 350 million cut flowers imported yearly into the United States come from Colombia (19).

The offspring of 8867 floriculture workers or their spouses included in a prevalence survey for adverse reproductive effects (18) was defined as the study population. A case was defined as a live birth, the child being still alive at the time of the study, for which one or more congenital malformations or other congenital defects were diagnosed by means of medical, physical, and paraclinical examination and a review of the medical records. A congenital malformation was understood to be any defect causing either esthetic or functional impairment and/or requiring surgical correction. Other congenital defects considered as cases were mental retardation, anthropometric anomalies, and birthmarks. A referent was defined as a live birth, the child being still alive at the time of the study, for which a congenital malformation or the other previously mentioned congenital defects had been excluded by means of a medical and physical examination. Two referents, matched by the age of the mother at delivery and pregnancy order, were selected for each case.

\section{Ascertainment and selection of the subjects}

The ascertainment and selection of the cases and referents were performed in two phases. First, 8867 floriculture workers ( 2951 men and 5916 women) were interviewed during a prevalence survey on adverse reproductive effects (18), and, of these, 3489 female workers and 1604 wives of male workers reported at least one pregnancy. Information on 13984 pregnancies was collected, and, of this number, 535 were reported by their parents to have resulted in "malformed children." From the children reported by their parents as "normal," 1070 were selected randomly as referents, matched by the age of the mother at delivery and by birth order.

In the second phase of the investigation a medical examination was carried out on both the "malformed" and the "normal" children as a means of verification of their status as cases or referents. For some of the cases the physical examination was complemented by a review of the medical records, consultation with medical specialists, and a paraclinical examination to obtain a final precise medical diagnosis.

The physical examinations were carried out by two physicians supervised and advised by a geneticist with clinical experience in teratology. A form containing an inventory of all congenital malformations by anatomic region, anthropometric measurements, developmental milestones, and indices of neurological func- tion was completed for each case and reference child. Photographs were taken of the children with malformations. All the information obtained in this way was reviewed by a clinical teratologist for a final diagnosis.

Compliance with the physical examination was $76 \%$ for both the cases and the referents. The remaining children could not be examined because their parents had left the floriculture companies and were untraceable; actual refusal of the examination occurred for $4.1 \%$ of the cases and $0.6 \%$ of the referents.

As a result of the examination process 216 of the "malformed" children $(\mathrm{N}=403)$ were considered normal, 33 were considered to have "other conditions," and 154 actually had a congenital malformation or some other congenital defect. Of the 817 "normal" children, 735 were normal, 14 had "other conditions," and 68 had a congenital malformation or some congenital defect.

The 154 children with congenital malformations or other congenital defects from the "malformed" group plus the 68 from the "normal" group constituted the 222 cases finally included in the study. From the 951 children classified as normal, 443 children individually matched by the age of the mother at delivery and pregnancy order were randomly selected to serve as referents.

The 222 cases were classified into the following two major categories: (i) major congenital malformations, ie, 159 cases, and (ii) other congenital defects such as birthmarks, anthropometric anomalies, and mental retardation, ie, 63 cases. The children in the first category fulfilled the study definition for structural congenital malformations; this category was further subclassified into several groups according to the known or suspected etiology of each condition, as follows: (i) associated with chromosomal abnormalities ( 1 case), (ii) monogenic origin (15 cases), (iii) conditions assumed to be of multifactorial origin ( 5 cases), (iv) conditions of unknown etiology ( 88 cases). The conditions grouped into the second category, "other congenital defects," did not strictly fulfill the definition of major structural congenital malformations; there may be some controversy as to whether they should be considered malformations or simply variations without functional or esthetic significance. Mental retardation was included, even though it is very difficult to ascertain whether it is due to a structural defect or whether it is only a functional defect. The second category was subdivided into (i) anthropometric anomalies, (ii) birthmarks, and (iii) mental retardation. Appendix 1 gives a list of the individual diagnoses of the 222 cases.

Two types of questionnaires were used. One was administered to the mothers (female workers and wives of the male workers), and the other to the fathers (male workers and/or husbands of female workers). The mothers' questionnaire contained general demographic information, detailed reproductive history, including information on family planning, and, for each preg- 
nancy under study, the questionnaire elicited information on the other variables listed in table 3 in the Results section, a general occupational history, and a detailed history of work in floriculture. This last item included length of time in each floriculture company, size of the company, types of job, especially during each of the three trimesters of the relevant pregnancy, and a history of acute pesticide intoxication and use of protective measures at work. The fathers' questionnaire contained the same information as the mothers', except for the information on pregnancy.

The questionnaires were filled out by specially trained interviewers from August 1982 to December 1983. The interview and physical examination were usually conducted at each floriculture company. The interviews were carried out blind (the interviewer did not know whether the subject was a case or a referent), and they lasted an average of $30 \mathrm{~min}$.

Compliance with the questionnaire was high for the mothers and low for the fathers. It was $100 \%$ for the mothers of cases and $95 \%$ for the mothers of referents, but it was only $42 \%$ for the fathers of cases and $36 \%$ for the fathers of referents. However, all the fathers who had worked or were working in floriculture were interviewed.

Since most of the parents of both the cases and the referents had worked in floriculture at one time or another (table 1), the study was oriented at estimating exposure (and degree of exposure) to pesticides during the specific pregnancy which terminated in the birth of a case or reference child. Exposure to pesticides during the relevant pregnancy was considered positive if the mother and/or the father had been working in floriculture during that pregnancy, and negative otherwise.

The procedure followed to estimate crudely the degree of exposure to pesticides has been described elsewhere (18). Briefly, it was based on the amount of pesticides used by each company, the length of exposure evaluated through the length of time worked in floriculture, and the type of job.

The floriculture companies were divided into three categories according to the amount of pesticides used, ie, low use or low exposure if the ratio of the total amount used to the total cultivated area was less than 120 , medium if this ratio was between 120 and 400 , and high if the ratio was greater than 400 .

The length of exposure was categorized into the two groups of less than one year and more than one year, on the basis of the information reported by the workers. The various jobs involved in the whole process of flower production were grouped into six categories in ascending order of degree of exposure on the basis of the results of a pilot study described elsewhere (report submitted for publication by Restrepo et al) as follows: (i) nonexposure: administrative jobs; (ii) low exposure: construction and maintenance of greenhouses, work in soil preparation, and in plant nurseries; (iii) high exposure: cultivation, sorting, and packing of flowers.
A survey on pesticide use conducted in the 58 floriculture companies participating in the study revealed that 127 different pesticides were used, most of them fungicides, and, of these, Captan (1,2,3,6 tetrahydro$\mathrm{N}$-trichloromethylthio-phthalimide) was the most widely used. It is thus obvious that exposure to pesticides among floriculture workers is multiple and complex. The interval between the exposure and the interview was long, ranging from 1 to 15 years.

\section{Statistical analysis}

The statistical analyses of the data were carried out in two phases. In the first phase, a matched set analysis was conducted. Relative risks were estimated with the use of the Mantel-Haenszel test (20). In the second phase, conditional logistic regression and the PECAN (parameter estimation through conditional probability analysis) program were used (21). All the variables were treated as categorical, and a two-sided significance test and $95 \%$ confidence intervals based on the asymptotic variance of the estimated parameters were calculated. As a first step, univariate analyses were conducted followed by multivariate analysis to control for confounding and to investigate possible interactions.

\section{Results}

The sex and age distribution is shown for the 222 cases and 443 referents in table 2 . The mean age of the male children was 10.3 years for the cases and 10.6 years for the referents. That of the female children was 9.2 years for the cases and 10.9 years for the referents. Fifty-two percent of the cases and $46 \%$ of the refer-

Table 1. Origin of preconceptional or prenatal exposure to pesticides for the cases and referents.

\begin{tabular}{lrrrrrr}
\hline & \multicolumn{2}{c}{ Cases } & & \multicolumn{2}{c}{ Referents } \\
\cline { 2 - 3 } \cline { 6 - 7 } & $\mathrm{N}$ & $\%$ & & $\mathrm{~N}$ & $\%$ \\
\cline { 2 - 3 } Total exposed & 81 & 36.5 & & 115 & 26.0 \\
Only mother exposed & 40 & 18.0 & & 56 & 12.6 \\
Only father exposed & 13 & 5.8 & & 32 & 7.2 \\
Both parents exposed & 28 & 12.6 & & 27 & 6.1 \\
Neither parent exposed & 141 & 63.5 & & 328 & 74.0 \\
\hline Total & 222 & 100.0 & & 443 & 100.0 \\
\hline
\end{tabular}

Table 2. Distribution of the cases and referents by sex and age.

\begin{tabular}{|c|c|c|c|c|c|c|c|c|}
\hline \multirow{3}{*}{$\begin{array}{l}\text { Age } \\
\text { (years) }\end{array}$} & \multicolumn{4}{|c|}{ Cases } & \multicolumn{4}{|c|}{ Referents } \\
\hline & \multicolumn{2}{|c|}{$\begin{array}{c}\text { Male } \\
\text { children }\end{array}$} & \multicolumn{2}{|c|}{$\begin{array}{l}\text { Female } \\
\text { children }\end{array}$} & \multicolumn{2}{|c|}{$\begin{array}{c}\text { Male } \\
\text { children }\end{array}$} & \multicolumn{2}{|c|}{$\begin{array}{l}\text { Female } \\
\text { children }\end{array}$} \\
\hline & $\mathbf{N}$ & $\%$ & $N$ & $\%$ & $N$ & $\%$ & $\mathbf{N}$ & $\%$ \\
\hline $\begin{array}{r}1-10 \\
11-20 \\
>20\end{array}$ & $\begin{array}{r}64 \\
45 \\
7\end{array}$ & $\begin{array}{r}55.1 \\
38.7 \\
6.0\end{array}$ & $\begin{array}{r}64 \\
35 \\
7\end{array}$ & $\begin{array}{r}60.3 \\
31.9 \\
6.5\end{array}$ & $\begin{array}{l}97 \\
96 \\
13\end{array}$ & $\begin{array}{r}47.0 \\
46.6 \\
5.3\end{array}$ & $\begin{array}{r}122 \\
96 \\
19\end{array}$ & $\begin{array}{r}49.4 \\
43.3 \\
7.2\end{array}$ \\
\hline Total & 116 & 100.0 & 106 & 100.0 & 206 & 100.0 & 237 & 100.0 \\
\hline
\end{tabular}


ents were male children. The reason for the relatively high age of both the cases and the referents is that the total offspring of floriculture workers were considered and not only those children born during the period when the parents worked in floriculture. No difference was observed in the age distribution or educational level of the parents of the two groups of children. Seventy-two percent of the mothers were under 40

Table 3. Distribution of known or suspected risk factors for congenital malformations among the cases and referents.

\begin{tabular}{|c|c|c|c|c|}
\hline \multirow{2}{*}{ Known or suspected teratogens } & \multicolumn{2}{|c|}{ Cases } & \multicolumn{2}{|c|}{ Referents } \\
\hline & $\mathrm{Na}^{\mathrm{a}}$ & $\%$ & $\mathrm{~N}^{\mathrm{a}}$ & $\%$ \\
\hline Consanguinity & 11 & 4.9 & 25 & 5.6 \\
\hline $\begin{array}{l}\text { Family history of congenital } \\
\text { malformation }\end{array}$ & 57 & 25.6 & 88 & 19.8 \\
\hline Diseases during pregnancy & 216 & 97.3 & 439 & 98.8 \\
\hline $\begin{array}{l}\text { Vaginal bleeding during } \\
\text { pregnancy }\end{array}$ & 216 & 97.3 & 438 & 98.6 \\
\hline Mumps during pregnancy & 1 & 0.4 & 2 & 0.4 \\
\hline Varicella during pregnancy & 1 & 0.4 & 2 & 0.4 \\
\hline Toxoplasmosis & 0 & 0.0 & 0 & 0.0 \\
\hline $\begin{array}{l}\text { X-ray exposure during } \\
\text { pregnancy }\end{array}$ & 5 & 2.2 & 6 & 1.3 \\
\hline Diazepam (Valium ${ }^{\circledR}$ ) & 12 & 5.4 & 3 & 0.6 \\
\hline Contraceptive pills & 2 & 0.9 & 0 & 0.00 \\
\hline $\begin{array}{l}\text { Pregnancy test with } \\
\text { estrogens }\end{array}$ & 21 & 9.4 & 30 & 6.7 \\
\hline Piperazine & 1 & 0.4 & 3 & 0.6 \\
\hline Vitamins & 125 & 56.3 & 271 & 61.0 \\
\hline Iron & 76 & 34.2 & 175 & 39.4 \\
\hline Other drugs & 69 & 31.1 & 87 & 19.5 \\
\hline Tobacco smoking & 74 & 33.3 & 123 & 27.7 \\
\hline Alcohol drinking & 63 & 28.3 & 114 & 25.6 \\
\hline Exposure to chemicals ${ }^{b}$ & 76 & 34.2 & 85 & 19.1 \\
\hline
\end{tabular}

a The numbers refer to pregnancies in which each variable was positive.

b Includes exposure to pesticides.

Table 4. Relative rișk (RR) and $95 \%$ confidence interval ( $95 \%$ Cl) for categories of congenital malformation and other congenital defects associated with pesticide exposure (mother's exposure during pregnancy versus nonexposure).

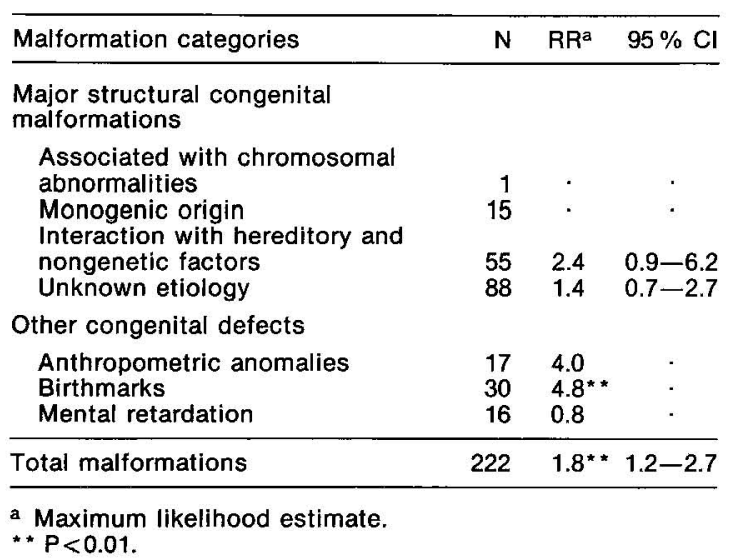

years of age, and $86 \%$ had only a primary school education or no formal education at all. About $64 \%$ of the fathers were under the age of 40 years, and $85 \%$ had only a primary education or no formal education at all. The distribution of the main risk indicators is shown for the cases and the referents in table 3.

\section{Univariate analysis}

Initially, a matched univariate analysis was carried out with the use of a dichotomous variable, ie, exposure versus nonexposure of the mother to pesticides during the relevant pregnancy. Table 4 shows the relative risks for the seven main categories of malformations. A statistically significant association was observed only for birthmarks. The relative risk is shown for specific types of malformations in table 5. The only significant association was for hemangioma. The principal characteristics of the hemangiomas of the exposed and unexposed children are shown in table 6 . No differences were observed concerning the size and type, and a slight excess was seen for the female children and the limbs among the exposed cases.

\section{Multivariate analyses}

Table 7 shows the results of the multivariate analysis. A set of different variables was added to the basic model containing the binary variable of mother's exposure versus mother's nonexposure to investigate possible interactions and to check for confounding. The selected maternal variables shown in table 3 did not affect the relative risk of 1.8 for total congenital malformations and pesticide exposure.

To investigate the presence of a dose-response relationship for an association between congenital malfor-

Table 5. Relative risk (RR) for some specific types of congenital malformation and other congenital defects associated with exposure to pesticides (mother's exposure during pregnancy versus nonexposure).

\begin{tabular}{lrc}
\hline Type of malformation & $\mathrm{N}$ & $\mathrm{RR}^{\mathrm{a}}$ \\
\hline Major congenital malformations & & \\
Hip dislocation & 26 & 2.9 \\
Microtia & 7 & $\cdot$ \\
Club foot & 4 & 0.6 \\
Interauricular communication & 8 & 1.6 \\
Oral clefts & 17 & $\cdot$ \\
Inguinal hernia & 16 & 0.5 \\
Cryptorchidism & 17 & 4.6 \\
Heart murmur & 9 & 2.1 \\
Polydactyly & 7 & 1.3 \\
Strabismus & 5 & $\cdot$ \\
Multiple anomalies & & \\
Mental retardation & 6 & $\cdot$ \\
With microcephaly & 10 & 0.28 \\
Without microcephaly & & \\
Birthmarks & 17 & $6.6^{*}$ \\
Hemangioma & 4 & 2.7 \\
Nevus & 4 & $\cdot$ \\
Mongolic spot & 5 & \\
Skin hyperpigmentation & & \\
\hline Maximum likelihood estimate. & & \\
* P=0.05-0.01. & &
\end{tabular}


Table 6. Characteristics of hemangioma in the exposed and unexposed cases.

\begin{tabular}{|c|c|c|c|c|c|c|c|c|c|c|}
\hline & \multicolumn{2}{|c|}{ Type } & \multicolumn{2}{|c|}{ Size $(\mathrm{cm})$} & \multicolumn{6}{|c|}{ Location } \\
\hline & $\begin{array}{l}\text { Cavern- } \\
\text { ous } \\
\text { (N) }\end{array}$ & $\begin{array}{l}\text { Capil- } \\
\text { lary } \\
\text { (N) }\end{array}$ & Mean & Range & $\begin{array}{l}\text { Head } \\
(\mathrm{N})\end{array}$ & $\begin{array}{l}\text { Neck } \\
(\mathrm{N})\end{array}$ & $\begin{array}{l}\text { Thorax } \\
\text { (N) }\end{array}$ & $\begin{array}{c}\text { Abdo- } \\
\text { men } \\
(\mathrm{N})\end{array}$ & $\begin{array}{l}\text { Lumbar } \\
\text { region } \\
\text { (N) }\end{array}$ & $\underset{(N)}{\operatorname{Limbs}}$ \\
\hline $\begin{array}{l}\text { Exposed cases }[N=12 \\
(9 \text { men, } 3 \text { women })]\end{array}$ & 1 & 11 & 0.7 & $0.5-2.0$ & 3 & 1 & 1 & - & 2 & 5 \\
\hline $\begin{array}{l}\text { Unexposed cases }[\mathrm{N}=5 \\
(3 \mathrm{men}, 2 \text { women })]\end{array}$ & - & 5 & 1.2 & $0.5-2.5$ & 2 & - & 1 & 1 & - & 1 \\
\hline
\end{tabular}

a Mother exposed to pesticides during the relevant pregnancy.

mations and exposure of the mother to pesticides during the relevant pregnancy, the variables which provided the largest reduction in the log-likelihood were selected. Two variables were thus selected, ie, length of exposure to pesticides, subdivided into two categories ( $<1$ year and $\geq 1$ year), and type of job, also grouped into two categories (low exposure and high exposure, according to the criteria given in the Subjects and Methods section). A dose-response relationship was found with these two variables as indicators of degree of exposure. Adjustment for any of the other variables did not influence these results.

When the main categories of congenital malformations were considered, the association and doseresponse relationship were present only for those conditions considered to be due to the interaction of hereditary and environmental factors and for conditions of unknown etiology. For specific types of malformations the small number of cases in each group did not allow a multivariate analysis.

In relation to the other findings of this study, ie, intrauterine exposure to diazepam, 15 mothers reported having taken diazepam during the study pregnancy ( 12 case mothers and 3 reference mothers). The diagnoses of the 12 cases were two cases of birthmarks and mental retardation, two cases of heart malformation, and one case with each of the following malformations: hip dislocation, microtia, cryptorchidism, polydactyly, nevus, and other.

\section{Discussion}

This study revealed that information collected on congenital defects retrospectively in interviews of parents of the children under study is very unreliable. In fact, validation of the report given by the parents by physical examination of the children revealed that $53 \%$ of those reported as malformed were normal and $8 \%$ of those reported as normal were malformed. Concerning the association between congenital malformations and parental pesticide exposure, no known teratogenic exposure has produced an increase in all types of malformations, and the analysis of this study was therefore oriented to look for an association between pesticide exposure and specific groups of malformations.
Table 7. Effect of pesticide exposure and other variables on congenital malformations (multivariate conditional logistic regression analysis). (RR $=$ relative risk)

\begin{tabular}{lcc}
\hline Variables & $\begin{array}{c}\text { RR for mother's } \\
\text { pesticide expo- } \\
\text { sure (adjusted } \\
\text { for other } \\
\text { variables) }\end{array}$ & $\begin{array}{c}\text { RR for other } \\
\text { variables (ad- } \\
\text { justed for } \\
\text { mother's pesti- } \\
\text { cide exposure) }\end{array}$ \\
\hline $\begin{array}{l}\text { Mother's pesticide exposure } \\
\text { Mother's X-ray exposure }\end{array}$ & $1.8^{* *}$ & - \\
$\begin{array}{l}\text { Mother's exposure } \\
\text { to diazepam }\end{array}$ & $1.8^{* *}$ & 1.6 \\
$\begin{array}{l}\text { Mother's pregnancy test } \\
\text { Mother's alcohol drinking }\end{array}$ & $1.8^{* *}$ & $7.8^{* *}$ \\
$\begin{array}{l}\text { Mother's smoking } \\
\text { Mother's exposure to }\end{array}$ & $1.8^{* *}$ & 1.3 \\
other drugs & $1.8^{* *}$ & 1.8 \\
Father's pesticide exposure & $1.8^{* *}$ & 1.2 \\
$<1$ year & $1.7^{* *}$ & $1.9^{* *}$ \\
$>1$ year & & 1.5 \\
\hline$* *$ P<0.01. & & 1.2 \\
\hline
\end{tabular}

By subdividing the phenotypic features, as described in the Subjects and Methods section, we avoided a misinterpretation of the results. In fact, the indiscriminate lumping of all phenotypic features would have produced a positive association (relative risk 1.8, $\mathrm{P}<0.01$ ) between the mothers' exposure to pesticides and all congenital malformations. After subdivision into categories it was clearly seen that this apparent association was explained only by the increased risk for hemangioma (relative risk $6, \mathrm{P}=0.018$ ).

The multivariate analysis showed a stronger association with higher degrees of exposure, as estimated by length of exposure and type of job after adjustment for other variables. The adjusted relative risk for all congenital malformations among those working for less than one year was 1.3 , and for those working one year or more it was 1.9. For the low-exposure jobs the adjusted relative risk was 0.6 , while that for jobs with high exposure was 2.1. When the mothers had had one year or more of exposure and had worked in highexposure jobs, the relative risk was 2.2 .

The results obtained in this study should be interpreted with caution because of two major difficulties. First, the cases included many different diseases, with different mechanisms and different etiologies, the vast majority of which remained unknown, and the num- 
bers of each type of malformation were too small to draw firm conclusions. Second, this was a multiexposure study in which exposure to a mixture of many pesticides has only been roughly estimated. These two features of the study make it impossible to detect associations between a specific disease and exposure to an individual chemical agent. In addition, the way in which the exposure was assessed may lead to an underestimation of the relative risk due to random misclassification (22-24). In fact, even though the status "exposed to pesticides" and "not exposed to pesticides" was carefully determined, given the multiexposure (the large number of products, the chemical nature of the products used, and the absence of a pattern of usage among the different floriculture companies), it is possible that a pregnancy that was "exposed to pesticides" was actually not exposed to an individual substance that can act as a teratogen. With the available information it was not possible to evaluate the role of random misclassification of relevant exposures on the relative risk detected in this study.

Given the design of the study, selection and ascertainment bias are not likely to explain the results. Recall bias with respect to exposures during pregnancy is a well recognized phenomenon in studies on congenital malformations $(5,25,26)$. In this particular study it might have occurred, as the interval between exposure and the interview was long, but it might have been less as far as pesticide exposure was concerned, since the occupational history of the mothers was taken in such a way that it was difficult for the mothers to associate this history with the medical examination of their children. However, recall bias may explain the association with diazepam and other drugs found in this study, as it has been reported recently that mothers of malformed children tend to report more accurately exposure to certain drugs and exposure to other factors than do mothers of reference children (26). Therefore, although an association between exposure to diazepam during pregnancy and certain congenital malformations has been reported (27-33), our findings can hardly be regarded as supportive of this possibility if we consider that the association was present for a heterogeneous group of congenital anomalies and that recall bias could not be excluded.

The possibility of confounding with other factors known or suspected to be associated with congenital malformations was dismissed after the multivariate analysis. However, we cannot exclude the possibility of confounding with other variables or potential teratogens which were not considered in the present study. In relation to the critical period of pregnancy in which the exposure occurred, there was, in all cases, continuous exposure during the three trimesters of pregnancy.

The association between maternal pesticide exposure and hemangioma detected in the present study is in- teresting. Capillary hemangiomas of the face can be a feature of the Sturge-Weber syndrome; cavernous hemangiomas can be a cosmetic problem or, if sufficiently large, the cause of problems such as thrombocytopenia (34). In the study cases, none of the former problems were present. The lesions detected were small and without any medical or cosmetic significance. The etiology of hemangiomas remains unknown, and 50 to $90 \%$ involute spontaneously before the child reaches the age of six to eight years $(35,36)$. A prevalence of $68 \%$ for capillary hemangioma has been reported for 4641 infants (37). No data were available on the prevalence in the age groups included in this study, but it is possible that the number does reflect underreporting. However, any underreporting may not have been very marked since birthmarks, including hemangiomas, were included in the "inventory" form used to record the results of the physical examination of all the children. It is also interesting that hemangioendothelioma in the heart, hemangiomas, or hemangioendothelioma in the spleen have been observed in experiments on mice exposed to Captafol, a homologue of Captan (38), which is the most widely used pesticide in the floriculture industry. However, the significance of this observation remains unknown.

The results of this study correspond with the results of other studies of congenital malformations and exposure to pesticides $(6-17)$, and they support experimental evidence which indicates that, surprisingly, fungicides, insecticides, and herbicides have, in general, a low embryotoxic potential at ordinary levels of use (4). However, malformation leading to neonatal death could not be assessed in the present study, and therefore the scope of the defects studied was somewhat limited.

However, it should be kept in mind that most of the epidemiologic investigations so far reported on this topic are related to exposure to phenoxy herbicides and that their results are not conclusive. Two ecological studies suggest an increase in birth defects after maternal exposure to dioxins in Seveso, Italy, and to phenoxy herbicides in Vietnam, but these studies have several methodological problems such as poor exposure assessment, no adjustment for confounding variables, and possible recall and ascertainment bias (39). On the other hand, in another ecological study in Hungary, no association between herbicide use and birth defects was found (8). To our knowledge, our study is the only one reported so far in which the presence of malformations and other birth defects was confirmed by a physical examination performed by a geneticist and a clinical teratologist.

In the area of reproductive epidemiology, as well as in other areas of study on the long-term effects of exposure to chemicals, exposure to pesticides must continue to be a matter for concern. 


\section{Acknowledgments}

We would like to express our gratitude to $\mathrm{Dr}$ LB Holmes, a clinical teratologist from the Massachusetts General Hospital, Boston, Massachusetts, in the United States for reviewing all the clinical malformations of the children with birth defects and making helpful comments on this manuscript; to Dr B Miller, National Cancer Institute, Bethesda, Maryland, in the United States for his valuable advice during the course of the study, and to Drs H Vainio and R Cabral, International Agency for Research on Cancer, Lyon, France, for their helpful discussions and encouragement.

This study was supported by the United States Environmental Protection Agency under contract 68-01-6251 between the Agency and the Pan-American Health Organization.

\section{References}

1. Kalter H, Warkany J. Congenital malformations: etiologic factors and their role in prevention. $\mathrm{N}$ Engl $\mathrm{J}$ Med 1983;30:424-31.

2. Wilson JG. Teratogenic effects of environmental chemicals. Fed Proc 1977;36:1698-703.

3. Nelson K, Holmes LB. Malformations due to presumed spontaneous mutations in newborn infants. N Engl J Med 1989;320:19-23.

4. Wilson JG. Environmental chemicals. In: Wilson JG, Fraser FC, ed. Handbook of teratology; vol I (General principles and etiology). New York, NY: Plenum Press, 1977:357-85.

5. Hemminki K, Vainio H. Occupational epidemiology and reproduction. In: Harrington JM, ed. Recent advances in occupational health. Edinburgh: Churchill Livingstone, 1984:117-30.

6. Nelson CJ, Holson JF, Green HG, Gaylor DW. Retrospective study of the relationship between agricultural use of 2,4,5T and cleft palate occurrence in Arkansas. Teratology 1979;19:377-84.

7. Field B, Kew $C$. Herbicide use and incidence of neural tube defects. Lancet 1979;1:1341-2.

8. Thomas HF. 2,4,5T use and congenital malformation rates in Hungary. Lancet 1980;2:214-5.

9. Brogan WF, Brogan CE, Dadd JT. Herbicides and cleft lip and palate. Lancet 1980;2:597.

10. Gordon JE, Shy CM. Agricultural chemical use and congenital cleft lip and/or palate. Arch Environ Health 1981;36:213-21.

11. Hanify JA, Metcalf P, Nobbs CL, Worsley KJ. Aerial spraying of 2,4,5T and human birth malformations: an epidemiological investigation. Science 1981;212:349-51.

12. Smith AH, Fisher BS, Pearce N, Chapman CJ. Congenital defects and miscarriages among New Zealand 2,4,5T sprayers. Arch Environ Health 1982;37:197200.

13. La Vecchio FA, Pashayan HM, Singer W. Agent orange and birth defects. N Engl J Med 1983;308:719-20.

14. Erickson JD, Mulinare J, McClain PN, et al. Vietnam veteran's risk for fathering babies with birth defects. JAMA 1984;252:903-12.

15. Roan CC, Matanoski GE, McIlnay CQ, et al. Spontaneous abortions, stillbirths and birth defects in families of agricultural pilots. Arch Environ Health 1984; 39:56-60.

16. Schwartz DA, Newsum LA, Markowitz Heifetz R. Parental occupation and birth outcome in an agricul- tural community. Scand J Work Environ Health 1986; $12: 51-4$.

17. Schwartz DA, Logerfo JP. Congenital limb reduction defects in the agricultural setting. Am J Public Health 1988;78:654-9.

18. Restrepo M, Muñoz N, Day NE, Parra JE, de Romero L, Nguyen-Dinh X. Prevalence of adverse reproductive outcomes in a population occupationally exposed to pesticides in Colombia. Scand J Work Environ Health 1990; 16:232-8.

19. Morse DL, Baker EL, Landrigan PJ. Cut flowers: a potential pesticide hazard. Am J Public Health 1979; 69:53-6.

20. Breslow NE, Day NE. Statistical methods in cancer research; vol I (The analysis of case-control studies). Lyon: International Agency for Research on Cancer, 1980. (IARC scientific publications; no 32.)

21. Storer BE, Wacholder S, Breslow NE. Maximum likelihood fitting of general risk models as stratified data. Appl Stat 1983;32:172-81.

22. Lemasters GK, Selevan SG. Use of exposure data in occupational reproductive studies. Scand J Work Environ Health 1984;10:1-6.

23. Lemasters GK. Types of exposure models and advantages and disadvantages of sources of exposure data for use in occupational reproductive studies. In: Lockey JE, ed. Reproduction: the new frontier in occupational and environmental health research. New York, NY: Alan R Liss Inc, 1984:67-79.

24. Hogue CJR. Reducing misclassification errors through questionnaire design. In: Lockey JE, ed. Reproduction: the new frontier in occupational and environmental health research. New York, NY: Alan R Liss Inc, 1984: $81-97$.

25. Hemminki K, Axelson O, Niemi ML, Ahlborg G. Assessment of methods and results of reproductive occupational epidemiology: spontaneous abortions and malformations in the offspring of working women. Am $\mathbf{J}$ Ind Med 1983;4:293-307.

26. Werler, MM, Pober, BR, Nelson, K, Holmes, LB. Reporting accuracy among mothers of malformed and nonmalformed infants. Am J Epidemiol 1989;129: $415-21$.

27. Weber LW. Benzodiazepines in pregnancy: academical debate on teratogenic risk. Biol Res Pregnancy Perinatol 1985;6:151-67.

28. Crombie DL, Pinsent RJ, Fleming DM, RumeauRouquette C, Goujard J, Huel G. Fetal effects of tranquilizers in pregnancy. Lancet 1975;2:198-9.

29. Rosenberg JM. Is it safe to utilize minor tranquilizers such as Librium Valium and meprobamate during pregnancy? NY State J Med 1975;75:1334-5.

30. Safra MJ, Oakley GP. Association between cleft lip with or without cleft palate and prenatal exposure to diazepam. Lancet 1975;2:478-80.

31. Saxen I, Saxen L. Association between maternal intake of diazepam and oral clefts. Lancet 1975;2:498.

32. Entman SS, Vaughn WK. Lack of relation of oral clefts to diazepam use in pregnancy. N Engl J Med 1984;310: $1121-2$.

33. Rivas F, Hernandez A, Cantu JM. Acentric craniofacial cleft in a newborn female prenatally exposed to a light dose of Diazepam. Teratology 1984;30:179-80.

34. Alper J, Holmes LB, Mihm MC. Birthmarks with serious medical significance: nevocellular nevi, sebaceous nevi, and multiple cafe au lait spots. J Pediatr 1979; 95:696-700.

35. Levy DM, Apfelberg DB. Hemangiomas in children. Am Fam Physician 1972;5:89-94

36. Leperchey F. Questions soulevées par l'origine et le développement des angiomes cranio-faciaux à la lumière des données embryologiques. Ann Oto Laryng 1973; 90:45- 54 .

37. Alper JC, Holmes LB. The incidence and significance 
of birthmarks in a cohort of 4,641 newborns. Pediatr Dermatol 1983;1:58-68.

38. Ito N, Ogiso T, Fukushima S, Shibata M, Hagiwara A. Carcinogenicity of captafol in BGC3F mice. Gann 1984;
75:853-65.

39. Sterling TD, Arundel AV. Health effects of phenoxy herbicides: a review. Scand J Work Environ Health 1986; 12:161-73.

\section{Appendix 1}

\section{Individual diagnoses for 222 cases}

Diagnosis
Conditions associated with chromosomal abnormalities
Down's syndrome
Conditions of monogenic origin
Achondroplasia
BOR syndrome
Congenital deafness
Congenital deafness with palpebral ptosis
Jarcho-Levin syndrome (spondylocostal dysplasia)
Multiple vertebral malformation
Nager's acrofacial dysostosis
Radio cubital synostosis
Saethre-Chotzen syndrome
Treacher Collins syndrome
Type E brachydactyly
Type D brachydactyly

Conditions assumed to be due to interaction between hereditary factors and nongenetic factors (multifactorial)

Cleft lip

Cleft palate and lip

Clubfoot

Hip dislocation

Interauricular communication

Legg-Calvé-Perthes disease

Microtia

Patent ductus arteriosus

Conditions of unknown etiology

Amputation of thumb

Anonychia and absence of phalanx

Anomalies of clavicle and velum palatinum

Coloboma

Cryptorchidism

Dermatomyositis

Entropion

Heart murmurb

Hypospadias

Hydrocephalus

Inguinal hernia
2

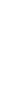

\begin{tabular}{lr}
\hline Diagnosis & $\mathrm{N}$ \\
\hline Klippel-Trenaunay-Weber syndrome & 1 \\
Microdactyly & 1 \\
Multiple anomalies & 5 \\
Multiple anomalies in fingers and metacarpus & 1 \\
Patella dislocation & 1 \\
Poland sequence & 1 \\
Polydactyly & 9 \\
Rectal fistula & 1 \\
Syndactyly & 1 \\
Strabismus & 7 \\
Vater association & 1 \\
Anthropometric anomalies &
\end{tabular}

Hypertelorism

Macrocephaly

Microcephaly

Subnormal size and weight 1

Birthmarks

Hemangioma

Hyperpigmentation

Hairy nevus

Mongolic spot

Ota nevus

Mental retardation

With microcephaly

Without microcephaly

Total

a $\mathrm{BOR}=$ brachiootorenal dysplasia.

b Murmurs were included as indicators of congenital heart disease according to the following criteria: (i) clinical graduation of the murmur: only those with an intensity greater than IIIIVI in children younger than five years of age or in children older than 5 years but without tonsillitis; (ii) when they were associated with other malformations, especially those of the central nervous or genitourinary systems.

Received for publication: 14 August 1989 